Weert, J. van, Dulmen, S. van, Bar, P., Venus, E. Interdisciplinary preoperative patient education in cardiac surgery. Patient Education and Counseling: 2003, 49(2), 105-114

\begin{tabular}{|c|c|}
\hline $\begin{array}{l}\text { Postprint } \\
\text { Version }\end{array}$ & 1.0 \\
\hline Journal website & http://dx.doi.org/doi:10.1016/S0738-3991(02)00091-5 \\
\hline Pubmed link & $\begin{array}{l}\text { http://www.ncbi.nlm.nih.gov/entrez/query.fcgi?db=pubmed\&cmd=Retrieve\&do } \\
\text { pt=Abstract\&list uids=12566204\&query hl=5\&itool=pubmed docsum }\end{array}$ \\
\hline DOI & 10.1016/S0738-3991(02)00091-5 \\
\hline
\end{tabular}

This is a NIVEL certified Post Print, more info at http://www.nivel.eu

\title{
Interdisciplinary preoperative patient education in cardiac surgery
}

\author{
JULIA VAN WEERT ${ }^{\mathrm{A}}$, SANDRA VAN DULMEN ${ }^{\mathrm{A}}$, PETER BÄR ${ }^{\mathrm{B}}$ AND ERICA VENUS ${ }^{\mathrm{B}}$ \\ ${ }^{a}$ NIVEL (Netherlands Institute for Health Services Research), P.O. Box 1568, 3500 BN, \\ Utrecht, The Netherlands \\ ${ }^{\mathrm{b}}$ Isala Clinics, location De Weezenlanden, P.O. Box 10500, 8000 GM, Zwolle, The \\ Netherlands
}

\begin{abstract}
Patient education in cardiac surgery is complicated by the fact that cardiac surgery patients meet a lot of different health care providers. Little is known about education processes in terms of interdisciplinary tuning. In this study, complete series of consecutive preoperative consultations of 51 cardiac surgery patients with different health care providers (physicians, nurses and health educators) were videotaped. The information exchange between patients and providers was analyzed directly from the video recordings by using an adaptation of the Roter Interaction Analysis System (RIAS) and a checklist of relevant informational topics. Results pointed to overlaps and gaps as well as to a lack of a patient-centered approach. The physicians were mostly overlapped by the nurses, who spent almost $30 \%$ of the time on talking about medical issues. Gaps were found in giving psycho-educational information and emotional support, needed to establish effective patient education. The findings provided a sound basis for developing guidelines and changes in the organization of the education process.
\end{abstract}

Author Keywords: Patient education; Interdisciplinary tuning; Quality of care; Cardiac surgery

\section{INTRODUCTION}

Numerous studies have been carried out to look at the educational needs of cardiac surgery patients [1 and 2]. Fulfilling patient's informational needs has long been acknowledged as an important factor in assisting recovery and reducing anxiety [3]. In addition, health care professionals are increasingly recognizing that providing effective information and advice is important for patients to cope with their illness [4]. Provided that education is patientcentered, i.e. that it is tailored to the individual patient and incorporates information as well as psycho-social factors, it also appears to contribute significantly to both cardiac and 
Weert, J. van, Dulmen, S. van, Bar, P., Venus, E. Interdisciplinary preoperative patient education in cardiac surgery. Patient Education and Counseling: 2003, 49(2), 105-114

psycho-social recovery [3 and 5]. Patient-centered medicine and its associated communication skills are defined as the key to develop sensitive and respectful medical care, which is not only linked to patient well-being, but also to physician well-being [6]. Besides, a patient-centered attitude has proved to save time as the interaction automatically focuses on for the individual patient most relevant issues [7]. So, the quality of the education depends not only on its content (instrumental communication) but also on the way in which it is provided (patient-centered and affective communication) [7 and 8].

The desire to reduce distress and anxiety in patients undergoing cardiac surgery has led to the development of several different preparatory information interventions. A number of studies demonstrated the effectiveness of these interventions. Mullen's meta-analysis of controlled trials of cardiac patient education showed that adherence to education principles (e.g. assuring that the content is relevant to the learner's interest, providing answers to personal questions) positively affects behavioral and clinical patient outcomes [9]. Stress can be reduced by allowing patients to talk about their concerns, which creates room for new information and gives the possibility to tailor the information to the individual patient. In providing information, attention should also be directed at the individual psycho-social determinants of behavior, such as beliefs, risk perception and emotional resistance [4]. Apparently, patient education and counseling have positive effects on cardiac and psychosocial recovery as long as the information provided fits the individual needs of the patient. A cardiac surgery patient is surrounded by a host of different providers such as nurses, cardiothoracic surgeons, anaesthetists, cardiologists, health educators and physiotherapists. This interdisciplinary system complicates the information process and leads to a greater need for coordination in the education provided [4]. Though sometimes overlaps and repetition are likely to enhance retention [10], there is a limit to the amount of information that patients can retain [3]. Accordingly, repeated information should be well-dosed and only concern relevant topics. Lauwers has shown that most orthopaedic surgery patients consider admission day as confusing and fatiguing, partly because the provided information on that day is too detailed [11]. In addition, Breemhaar observed that the provision of information on admission day to patients undergoing cholecystectomy or herniorraphy did not match their needs at that time [12]. Little is known about preoperative education in cardiac surgery patients in terms of interdisciplinary tuning, i.e. the extent in which health care professionals from different disciplines adjust the education they provide to each other. There might be overlaps, gaps and inconsistencies between different health care providers in the content of preoperative patient education to cardiac surgery patients, which prevent a patient to become adequately informed. A few years ago, 46 cardiac surgery patients admitted for cardiac surgery to the Isala Clinics in The Netherlands completed a questionnaire about their satisfaction with the quality of care. Thereby, $38 \%$ of them expressed dissatisfaction, especially with overlaps and inconsistencies in the information they received on admission day and with repeated questions asked by different health care providers. Apparently, the provided information did not fit their individual needs. The purpose of this study is to make a content analysis of interdisciplinary preoperative education in cardiac surgery and to determine whether or not the provided education lack interdisciplinary tuning and fit the patients' informational needs. The study focuses on preoperative preparation on admission day, i.e. the day before surgery. On admission day, most cardiac surgery patients feel anxious and stressed and find it difficult to grasp the huge amount of information they are confronted with. These feelings are likely to increase when the education is insufficient or not tuned to the patients' informational needs [1]. In this study, patients' questions are interpreted as a verbal cue for the patients' informational needs. Specifically, the following research questions will be addressed:

1. What are the actual overlaps, gaps and inconsistencies between the preparatory information from physicians, nurses and health educators?

2. What kind of information do cardiac surgery patients ask for on admission? 
Weert, J. van, Dulmen, S. van, Bar, P., Venus, E. Interdisciplinary preoperative patient education in cardiac surgery. Patient Education and Counseling: 2003, 49(2), 105-114

\section{METHODS}

\subsection{Subjects}

This article focuses on planned cardiac surgery patients (CABG and/or valve replacement), waiting at home for admission at one of the 13 heart centers in The Netherlands, i.e. the Isala Clinics, location "De Weezenlanden”. The research group was limited to surgery patients coming for CABG and/or valve replacement in order to create a homogeneous group. Preand postoperative care for both groups is similar. Subsequently, the content of admission interviews with these patients and their relatives is comparable. Patients transferred for surgery from other hospitals as well as emergency surgeries were excluded, because the organizational structure to educate these patients differs remarkably from educating paths for waiting-list patients. During eight weeks, all 85 patients planned for cardiac surgery were asked to participate in the study and to give written permission to videotape a series of encounters with different health care providers. Therefore, three consecutive assessments on admission day were selected, firstly with a health educator, secondly with a physician (cardiothoracic surgeon resident) and lastly with a nurse. Health educators inform the patients' family during surgery by telephone. On admission day, health educators provide the patients and their family with practical information about the surgery (e.g. time, duration) and about the patients' stay on the Intensive Care Unit (ICU) during one or two nights after the surgery (e.g. rules, visiting-time). Physicians have to carry out a last physical examination and provide the patients with medical information. The main task of nurses during the admission interview is to supply information about the organization, services and rules of the cardiac surgery ward, where the patients stay before the cardiac surgery and after the ICU-period. Besides, they inform the patients about the preparatory care they will receive before the surgery as well as the care and rehabilitation after the surgery. These three encounters were considered the most important education moments on admission day. Other visits of health care providers on admission day, e.g. anaesthetist and physiotherapist, were excluded because their education responsibilities were more clear, their visits were unplanned and usually not in the presence of relatives.

About a week before admission, the patients received an informed consent form which explained the nature of the study and their right to withdraw at any time. The day before admission, the patients were contacted by phone to provide further explanation about the research. Thereby, 68 participants (80\%) gave written consent and completed a questionnaire about demographic aspects. Included patients were followed on admission day. The health educator, physician and nurse they were going to visit, were asked to record the consultation on video. To record all encounters, portable video cameras were placed in different consulting rooms. When the patient entered the consulting room, the health care provider switched on the video camera. In some cases, the video camera was switched on by the researcher, but the researcher left the room before the consultation started. Directly after the consultation, the health care providers were given the opportunity to disclose their feelings with respect to the video-recording. Although, in general, the providers experienced some stress in advance, the majority reported afterwards that stress did not really affect their behavior. They described the encounter as a common and representative interview. None of the health care providers, scheduled by the hospital, refused to be included in the study. There were 4 physicians ( 1 female, 3 male), 23 nurses ( 17 female, 6 male) and four health educators (all female) who participated.

\subsection{Observation scheme}

The communication between the health care providers, the patients and the relatives was measured by two independent raters directly from the video-recordings using the CAMERA computer system, which is especially designed for coding behavioral interactions from video-recordings [14]. The verbal content of the encounter was analyzed using an adaptation of the Roter Interaction Analysis System (RIAS). This system gives the opportunity to code both health care provider and patient communication [13]. The adapted version included 17 
Weert, J. van, Dulmen, S. van, Bar, P., Venus, E. Interdisciplinary preoperative patient education in cardiac surgery. Patient Education and Counseling: 2003, 49(2), 105-114

behavioral categories for the provider and 15 behavioral categories for the patient and the relatives ( Table 1). The total length of all utterances was measured and coded into one of the 32 categories. When more than one consecutive utterance was classified in the same category, the total length of the utterances in the same category was computed. This provided a realistic view on the actual speaking time about related items. In addition, the number of patients questions was measured. The content of the clusters has been determined in close collaboration with a project group, existing of the nurse manager cardiac surgery/cardiology, a cardiothoracic surgeon, the project leader 'educating cardiac surgery patients', a head nurse, a health educator and the coordinator patient education. The project group supplied medical items (eight clusters), nurses' items (six clusters) and health educators' items (four clusters), as part of existing guidelines and daily practice.

Furthermore, we designed categories referring to communication aspects needed to establish effective education, such as psycho-social items and checks, i.e. assessments of patients' knowledge, expectations and understanding (five clusters). The issues covered by the psycho-social clusters (including socio-emotional verbal utterances) and clusters concerning checks were based on literature [3, 4, 9, 15 and 16]. Finally, categories were made to code other information that appeared to be given or to be questioned, such as lifestyle advices and information about admission day (nine clusters).

\section{[TABLE 1]}

In addition to the categorizing of verbal communication, the duration of extra-consultation interruptions and, if carried out, physical examination was rated. Besides, we developed a checklist with 123 specific content categories of provider conversation. They were all subitems of the 17 distinguished provider categories of the RIAS-adaptation. After computerized (RIAS) coding, the observer marked those education topics on the checklist that had been discussed during the encounter. Finally, patient-centeredness was measured using six five-point Likert scales indicating how much the specialist took the patients' and the relatives' needs in consideration (varying from 1 'not at all' to 6 'excellent').

\subsection{Analysis}

Data analysis of the video-observations was done by using descriptive statistics. The length of providers' and patients' communicative utterances within the specific categories were proportionate to the total length of the conversation. Oneway Anova analysis was used to test whether there was a statistically significant difference between the three provider groups (Table 2, Table 3 and Table 6). To identify actual overlaps and gaps in education of the same patient, results from the checklist were aggregated to patient level. Subsequently, descriptive statistics were used to show percentages of patients that did not receive specific information from one of the three videotaped health care providers or, on the contrary, that received certain information two or three times from different providers (Table 4 and Table 5). To test the differences in background characteristics of included and dropped-out patients, t-tests and $\mathrm{x}^{2}$ analysis were used.

\section{[TABLE 2]}

\section{[TABLE 3]}

\section{[TABLE 4]}

[TABLE 5] 
Weert, J. van, Dulmen, S. van, Bar, P., Venus, E. Interdisciplinary preoperative patient education in cardiac surgery. Patient Education and Counseling: 2003, 49(2), 105-114

\subsection{Reliability of the observations}

Pearson correlations were used to measure the interobserver reliability of the computerized (RIAS) coding and patient-centeredness. Interobserver reliability of the checklist-items was measured by using Cohen's Kappa. Two observers rated the same 15 videotaped interviews with health educators (10\% of the total number of videotaped admission conversations). Interobserver reliability was not measured for the verbal communication by providers and patients, which took up less than $2 \%$ of the time [17]. The overall average pair-wise Pearson correlation coefficient for the verbal behaviors by health care providers and patients (RIAS) was 0.91 (range $0.71-0.99$ ) and for patient-centeredness 0.93 (range $0.87-1.00$ ). The overall average Cohen's Kappa between the two observers for the checklist-items was 0.78 (technical equipment on ward: 0.39; technical equipment on ICU: 0.44; the other checklistitems: range 0.55-1.00). For 19 checklist-items Cohen's Kappa could not be counted, because one or two observers had no variation in their score.

\section{RESULTS}

\subsection{Sample characteristics}

68 patients were videotaped on admission day. Some of the series were incomplete for organizational or technical reasons: either the tape was of insufficient quality for analysis or the encounter was not recorded due to logistical problems. Finally, from 51 patients complete series of visits could be analyzed, resulting in 153 videotaped visits. Complete series were particularly necessary to identify actual informational overlaps and gaps within the same patient.

Four physicians videotaped an average of 13.0 patients (range 10-16), 23 nurses an average of 2.3 patients (range 1-6) and four health educators an average of 13.0 patients (range 222). The study sample consisted of 41 male (80.8\%) and 10 female (19.2\%) cardiac surgery patients with a mean age of 62.6 years (range 36-79 years, S.D. 9.4). 34 patients (66.6\%) were accompanied by one relative ( $52.9 \%$ spouse, $13.7 \%$ others), 16 patients (31.3\%) by two relatives (23.5\% including spouse, $7.8 \%$ just others) and one patient (2.0\%) by three relatives (including spouse). No one came alone. None of the included patients were scheduled for cardiac re-operation. Thereby, 31 patients (60.8\%) had a surgical history, but not in cardiac surgery. There were no significant differences between included patients $(\mathrm{n}=51)$ and dropouts $(n=17)$ with regard to the background characteristics.

\subsection{Verbal contributions}

Table 2 shows characteristics of the encounters by the different health care providers. The average visit length of the consultations was $12.8 \mathrm{~min}$ for the encounters with health educators, $26.0 \mathrm{~min}$ for the physicians' encounters and $32.8 \mathrm{~min}$ for the nurses' encounters. Due to physical examination, the average period of silence was highest during the physicians' encounters (7.4 min; 31.1\% of total visit length). The average verbal contribution of the patients (including relatives) was minimal in the health educators' encounters (1.6 min; 10.8\%), but more prevalent in the physicians' encounters (7.8 min; 30.2\%) and the nurses' encounters (10.2 min; 30.7\%). Though there was a difference in the providers' verbal contribution in relation to the total visit length between physicians (37.9\% of total visit length) and health educators (78.9\%), the average speaking time of physicians and health educators did not differ a lot from each other. The duration of the providers' verbal utterances was 10.6 min for physicians and 9.8 min for health educators. However, the physicians spent relatively a lot of time on collecting information (4.3 min; $40.9 \%$ of physicians' verbal contribution consisted of questions), while the health educators mainly provided information (9.4 min; 95.6\% of their verbal contribution). Related to the total count of verbal behavior of both the physicians' and the patients' conversational contributions, 10.8 min (58.9\%) of the total communication during the physicians' encounters existed of physician questions and patient answers. The nurses, with an average speaking time of 
Weert, J. van, Dulmen, S. van, Bar, P., Venus, E. Interdisciplinary preoperative patient education in cardiac surgery. Patient Education and Counseling: 2003, 49(2), 105-114

$17.0 \mathrm{~min}$ (52.3\% of total visit length) per encounter, were both educating and questioning: 12.9 min (75.6\%) of the nurses' verbal contribution was spent on education, 2.8 min (16.7\%) on posing questions and $1.3 \mathrm{~min}(7.7 \%)$ on other communication (social talking). Related to the total verbal communication (including patient answers) $9.7 \mathrm{~min}$ (35.5\%) of the total speaking time was spent on questions from the nurses and answers from the patients.

\subsection{Content analysis}

Table 3 gives information about the content of the encounter with different health care providers. In this table the minutes spent on conversational topics are displayed as percentages of the total verbal communication time during an encounter. Coherent clusters of providers' and patients' communication are joined together. This means that patient communication and provider communication concerning the same topic were combined by counting the total speaking time of the provider and the patient about the same subject (see Table 1 for coherent clusters). The communication between the physicians and the patients appeared to be primarily about medical topics. However, in nurses' encounters, almost onethird of the time (29.8\%) was spent on medical topics as well. Psycho-social issues and checks, both known as important topics to reduce anxiety and to guarantee effective education, covered only a small part of the conversation, especially in the encounters of the physicians and the health educators. The psycho-social categories include, for instance, questions about feelings to help patients express their fears, information about psycho-social consequences of the cardiac surgery and socio-emotional utterances like empathizing, reassuring or other emotional support. The category 'check' includes questions about the patients' knowledge, expectations and understanding, which enables the provider to clarify misperceptions.

Table 4 provides more detailed information about the percentages of the patients receiving such psycho-educational care. There seemed to be a gap in providing psycho-social care and emotional support. More than half of the patients (51.0\%) did not receive a single psychosocial question (e.g. “Are you getting nervous about tomorrow?”) during the three videotaped encounters. The majority of the providers did not explore the level of anxiety or even moot the subject of being worried (e.g. "many patients are anxious about surgery. Do you have particular concerns you would like to discuss?”). Thereby, $76.5 \%$ of the patients was not informed at all about psycho-social consequences of the cardiac surgery. There also seemed to be a gap in tuning the information to individual needs. The nurses were the only providers who sometimes checked to what extent the patient already had been informed, but still only in one-third of the cases (33.3\%). Less than a quarter of the patients (23.5\%) were asked for their informational needs or other expectations. Though almost three-third of the patients (74.5\%) received a short ask for understanding from one of the providers (e.g. "Am I clear?”) only three patients (7.8\%) got such a check from both the physician, the nurse and the health educator. A more specific assessment of understanding (e.g. "Is it clear to you how long you will stay on the ICU?”) was hardly done (in $78.4 \%$ of the cases by none of the providers).

Based on the checklist, more information was obtained about details of the overlaps. Most overlaps were found in talking about medical topics by the physicians and the nurses. Especially, many questions in medical history taking were asked twice. Only in five cases (9.8\%), the nurses copied medical information from the medical file, which precluded asking the same questions again. Table 5 gives the percentages of the patients who received specific questions both by the physician and by the nurse, by the physician only or by the nurse only. Because health educators only spent $1.5 \%$ of the time on medical history taking, they are not included in this table. For the interpretation of this table it is important to know that only medical questions that were really formulated as a new question (e.g. "Have you ever been operated before?”) were coded as 'medical question'. Medical questions that aimed to verify certain information (e.g. "I see you have never been operated before?") were coded as 'check' and not measured as overlap. 
Weert, J. van, Dulmen, S. van, Bar, P., Venus, E. Interdisciplinary preoperative patient education in cardiac surgery. Patient Education and Counseling: 2003, 49(2), 105-114

Table 5 also illustrates some of the variation we found within the groups of physicians and nurses (see the wide standard deviations in Table 3). Topics like "previous visited hospitals", "length/weight", "alcohol consumption” and "home situation after discharge” were variably discussed by the providers. For example, 13 patients (25.5\%) were asked about the consumption of alcohol by both the nurse and the physician, 14 patients $(27.5 \%)$ by none of the providers, 20 patients (39.2\%) just by the nurse and 4 patients $(7.8 \%)$ just by the physician.

Not only in questioning, but also in patient education, there seemed to be a lot of overlaps. For instance, $96.1 \%$ of the patients were told by two or (all) three providers that the physiotherapist would come around today. To almost one-third (31.4\%) of the patients the possibility to be transferred to another hospital a few days after surgery was mentioned by all providers, and another $29.5 \%$ was educated about this twice. Almost three-quarters of the patients were informed more than once about the length of stay on the ICU (74.5\%) and about the prohibition to be left alone after discharge (70.6\%). Also, $60.7 \%$ of the patients were informed two or three times about the name of the cardiothoracic surgeon that probably would do the surgery and $33.4 \%$ about the length of stay in the hospital.

Inconsistencies were found in the topics mentioned by different providers. For instance, one said that the physiotherapist would visit the patient in the afternoon, another told the same patient there would be a collective meeting at 2 o'clock. Information about the length of stay in hospital differed from 5 to 10 days, which can partly be attributed to differences in the way of counting the first day (admission day or the first day after surgery). Some providers told the patient "You should never be alone during the first 2 weeks after discharge", others said "Especially at night, it is better not to be alone". Though most of the inconsistencies seemed to be rather innocent, they usually led to confusion on the part of the patient.

\subsection{Patients' questions and patient-centeredness}

Patients' questions formed just a small part of the total verbal communication (3.2\%, S.D. 2.0). Per visit, the physicians received an average of 11.7 questions, the nurses 21.0 and the health educators 8.3 (including short requests for clarification or confirmation). All patients' questions were measured and categorized. More detailed information about the nature of those questions is presented in Table 6. To get a realistic view on the information the patients asked for on admission day, the duration of patients' questions about specific topics are displayed as percentages of the total time spent by the patients on asking questions during the series of three encounters. Patients mostly asked for short-term, practical information. Thereby, $40.7 \%$ was directly related to the surgery and the stay on the ICU (15.3\% practical questions about surgery and ICU, $13.9 \%$ medical questions about surgery, $11.5 \%$ questions about preparation for surgery), e.g. about length of surgery, anaesthesia, first visit after surgery, number of visitors on the ICU, premedication or how to remove the wedding ring. Thereby, 36.7\% considered general questions about the cardiac surgery ward (18.2\%) or about hospital stay after surgery (18.5\%), e.g. about the room on the ward, length of stay in the hospital or the possibility to be transferred to another hospital. There were hardly any psycho-social questions or 'long-term' questions about what to expect from daily activities and recovery after discharge. The table shows that, on average, more than half of the total time of patients' questions was spent in the nurses' encounters, though they were the last interlocutor at admission day. In addition, the mean overall score for patient-centeredness on a six-point Likert scale, given by the observers, was highest for nurses (3.1) and lowest for health educators (1.8), which is in conformity to the patients' verbal contributions. The physicians' mean score was 2.2. 
Weert, J. van, Dulmen, S. van, Bar, P., Venus, E. Interdisciplinary preoperative patient education in cardiac surgery. Patient Education and Counseling: 2003, 49(2), 105-114

\section{[TABLE 6]}

\section{DISCUSSION}

\subsection{Interdisciplinary tuning}

The purpose of this paper was twofold, to explore the content of interdisciplinary preoperative patient education in cardiac surgery and to gain insight into the information cardiac surgery patients ask for on admission day. Results showed that the information provided by the different health care providers covered a wide range of topics. Overlaps were found in gathering and providing information by the physicians, the nurses and the health educators. Especially between the physicians and nurses, there appeared to be a huge overlap in medical history taking. Even though other preoperative visits with the physicians, who probably discussed similar medical topics, are left out of consideration, more than twothirds of the patients had to answer questions about medication, health care problems, previous surgeries, allergy and smoking twice, close after each other, on admission day. Obviously, from the perspective of health care providers it is important to gather information about certain issues. Many of the questions that were duplicated by physicians and nurses are critical for providing safe care. However, from the perspective of patients it would be more satisfying when nurses, instead of asking the same questions again, just checked whether the information they got from the medical file is correct or not. This will not only save time during the admission interview and prevent patients from getting tired of answering the same questions again, but also inspire confidence in the teamwork of health care providers. The quality of care may be improved as there will be an extra verification on the preciseness of the gathered information. Besides, a discussion among health care providers and policy makers for the safe elimination of some of this duplication will promote further efficiencies.

Results also pointed to overlaps in the provision of information by different health care providers. The patients received so much information all at once, that they might have difficulties to process the information adequately. In this study, health care providers seemed to be unaware of the overlaps, which possibly can be explained by a lack of coordination. A failing coordination among different health care providers was also evidenced by Mudde, who found an insufficient coordination in patient education to hospital patients in general [18]. Next to negative effects of overlaps to the effectiveness of patient education on patient level, overlaps are also undesirable in terms of organizational aspects and time-efficiency [9].

Gaps were mainly found in providing psycho-educational care. Although, anxiety can pose a barrier for patient learning and more anxious patients rate their perceived knowledge level lower [19], most of the health care providers did not examine the level of anxiety. Besides, the health care providers hardly provided any psycho-social information or emotional support. Though (instrumental) information can be considered as one of the domains of psycho-educational content, it has been shown that treatments with elements of content from more domains (including psycho-social support) have larger beneficial effects on health outcomes [16 and 20]. In the present investigation of patient education in cardiac surgery, there seemed to be a lack of a patient-centered approach. Careful assessment of (perceived) knowledge, beliefs and understanding is important [19], but such checks were rarely done. To make the learning process more effective, providers need to pay more attention to the patients' feelings of anxiety that accompany cardiac surgery and to the patients' informational needs.

\subsection{Patients' informational needs}

Most studies on preoperative patients' needs assess patients' opinion prospectively (before admission) or retrospectively (after discharge). In this study, we focussed on actual patient behavior on admission day. Half of the patients' questions were addressed to the nurses, which suggests that patients feel more stimulated by them to contribute to the conversation 
Weert, J. van, Dulmen, S. van, Bar, P., Venus, E. Interdisciplinary preoperative patient education in cardiac surgery. Patient Education and Counseling: 2003, 49(2), 105-114

than by the other providers. As the physicians were dominating the conversation by asking a lot of questions and the health educators mainly soliloquized, both allowed the patients less room to talk than the nurses did. In accordance with our findings, Breemhaar reported that, during admission, surgical patients often direct their questions to nurses, although they are obviously meant for a physician. The observational part of their study showed that physicians are often reserved in offering information [12].

The results of our study showed that psycho-social questions and 'long-term' questions (e.g. about daily life after discharge) were hardly posed. The patients seemed to be mostly interested in short-term, practical information. As the patients' questions might arise in interaction with the providers' education, the content of the patients' questions was possibly (also) guided by the topics launched by the health care providers. Our results are partly strengthened by Lamarche [19] and Breemhaar [12]. In Lamarche’s study, using preadmission telephone interventions, patients scheduled for an elective cardiac surgery spoke in general terms about fear of having an endotracheal tube after surgery, fear of pain and of dying during surgery. Others wanted specific information about medical details. Few asked anything about pain control, length of stay or what to expect during convalescence. Breemhaar held open-ended patient interviews with surgical patients during admission. He also considered fear of aspects of surgery (e.g. fear of anaesthesia, postoperative pain and of side effects) and the wish to get (more) information about medical details as most important aspects expressed by the patients. In our study, the patients indeed asked quite a lot of medical questions. The patients may try to control their fears by asking medical questions. Yet, contrary to both Lamarche's and Breemhaar's studies, the patients hardly mentioned fear of surgical aspects to the health care providers. This may be explained by the minimal psycho-social attention, expressed by the health care providers, which does not seem to coincide with the patients' needs for psycho-social support and may prevent them from expressing their fears. Besides, patients may view it as questioning the competence of the health care provider if they initiate the discussion of being anxious or distressed. A stronger sense of the patients' level of emotional distress might be achieved by exploring the patients' feelings and beliefs more actively.

\subsection{Study limitations}

A few methodological issues are worth mentioning. Our sample size might have diminished the generalizability of the findings. The number of different health care providers was not big enough to take the similarity among encounters by one health care provider into account. Whether the results can be generalized to interdisciplinary education in other heart centers needs to be sorted out in future studies. However, though there are no previous studies investigating interdisciplinary patient education to cardiac surgery patients, the results do not markedly differ from two previous studies in interdisciplinary surgical patient education to patients undergoing less severe (not life threatening) surgeries [11 and 12].

In this study, a content analysis of interdisciplinary patient education in cardiac surgery was made. Patient education is an essential part of hospital's medical care. Complete assessment of the quality of education should incorporate aspects of the organizational structure of the care (e.g. organization size, use of standards, interdisciplinary tuning, timing and scheduling, perceived workload), the care process (structure and content of the interpersonal education, education time) and patient-related outcomes (clinical outcome, knowledge, satisfaction). Our study focused on interdisciplinary tuning and the content of the education. Recent studies into the relationships between, at the one hand, organization characteristics in health care organizations and general practice and, at the other hand, (micro-level) outcome and process of medical care [21 and 22] indicate the feasibility and relevance of examining the role of structural and organizational factors in the content and outcome of micro-level health care processes like patient education. Further investigation is recommended to determine how organizational aspects are related to the process and outcome of patient education. Furthermore, it would be useful to examine whether the cardiac recovery of patients who 
Weert, J. van, Dulmen, S. van, Bar, P., Venus, E. Interdisciplinary preoperative patient education in cardiac surgery. Patient Education and Counseling: 2003, 49(2), 105-114

have been "educated adequately", i.e. tailored to their informational needs, differs from those who have not been.

\subsection{Practice implications}

The multi-disciplinarity of the care for cardiac surgery patients proved indeed to complicate the information process. Apparently, it is not always clear who is responsible for what kind of information at what moment, which causes overlaps and gaps. Besides, the education seemed not tailored to the patients' needs, which makes it less effective. Based on these findings, guidelines were developed for all health care providers involved in cardiac surgery care. This interdisciplinary information protocol contains a list of issues that should be raised by different providers at different education moments. The information protocol is located near the patients' bedside, where providers can mark the information they have been given. These guidelines are also integrated in a Patient Information Dossier (PID): an interdisciplinary information booklet on patient education for cardiac surgery patients. Furthermore, changes were made in the organization of the education process: An outpatient clinic was started up. Physicians, health educators and patients meet each other a few weeks before surgery in order to spread the information and to save time on admission day. During this visit, patients receive their PID to prepare for the surgery. The PID as well as the organizational changes are developed and implemented in close collaboration with the project group. A postmeasurement will show whether the guidelines, now tailored to the hospital, have improved the education.

Patient education in cardiac surgery and interdisciplinary tuning can also be improved by other implementation strategies as (postgraduate) communication skills training or structural interdisciplinary consultation. Which implementation strategy will be chosen will depend on the needs of the health care organization. In any case, close collaboration with representatives in the field and systematic implementation are essential to produce effectiveness. Thus far, in medical and nursing training, communication programs primarily focus on teaching general communication skills or, especially in the curriculum of medical specialists, on acquiring technical-medical skills and knowledge. More attention should be paid to the context in which communication takes place, i.e. to specific needs of patients, to specific goals that have to be achieved or to characteristics of the working environment [23]. To receive long-term improvements, it seems advisable to add communication training courses to the medical curriculum, in order to make residents (more) conscious of the importance and effects of their style. To achieve a more patient-centered approach by both physicians and nurses, structural attention should be paid to communication skills that teach providers how to deal with emotional distress of patients.

\section{ACKNOWLEDGEMENTS}

The authors greatly appreciate the participation of the health care providers and the patients who gave permission to videotape their medical visits.

\section{REFERENCES}

1. H. Goodman , Patients' perceptions of their educational needs in the first six weeks following discharge after cardiac surgery. J. Adv. Nur. 25 (1997), pp. 1241-1251. 2. E.A. Grossi, A.C. Galloway, K. Kallenbach, J.S. Miller, R. Esposito, D.S. Schwartz et al., Early results of posterior leaflet folding plasty for mitral valve reconstruction. Ann. Thorac. Surg. 65 (1998), pp. 1057-1059.

3. C. Read, Patients' information needs in intensive care and surgical wards. Nurs. Stand. 12 (1998), pp. 37-39.

4. H.W. Van den Borne, The patient from receiver of information to informed decisionmaker. Patient Educ. Couns. 34 (1998), pp. 89-102. 
Weert, J. van, Dulmen, S. van, Bar, P., Venus, E. Interdisciplinary preoperative patient education in cardiac surgery. Patient Education and Counseling: 2003, 49(2), 105-114

5. S.A. Cupples, Effects of timing and reinforcement of preoperative education on knowledge and recovery of patients having coronary artery bypass graft surgery. Heart Lung 20 (1991), pp. 654-660.

6. D. Roter , The medical visit context of treatment decision-making and the therapeutic relationship. Health Exp. 3 (2000), pp. 17-25.

7. D.L. Roter, J.A. Hall, D.E. Kern, L.R. Barker, K.A. Cole and R.P. Roca , Improving physicians' interviewing skills and reducing patients' emotional distress. A randomized clinical trial. Arch. Intern. Med. 155 (1995), pp. 1877-1884.

8. Bensing JM. Doctor-patient communication and the quality of care. Utrecht: Nivel, 1991.

9. P.D. Mullen, D.A. Mains and R. Velez , A meta-analysis of controlled Trials of Cardiac Patient Education. Patient Educ. Couns. 19 (1992), pp. 143-162.

10. E.J. Robinson and M.J. Whitfield, Contributions of patients to general practitioner consultations in relationship to their understanding of doctor's instructions and advice. Soc. Sci. Med. 27 (1988), pp. 895-900.

11. H. Lauwers and N.P. Maris, De totale heup-operatie en de voorlichting. (The total hip operation and education). TVZ 2 (1990), pp. 56-59.

12. B. Breemhaar, H.W. van den Borne and P.D. Mullen , Inadequacies of surgical patient education. Patient Educ. Couns. 28 (1996), pp. 31-44.

13. Iec ProGAMMA. User Manual CAMERA: a system for collecting and correcting behavioural data. Groningen: Iec ProGAMMA, 1994.

14. Roter D. The Roter method of interaction process analysis. Baltimore: Johns Hopkins University, 1989.

15. T.M. Davis, T.O. Maguire, M. Haraphongse and M.R. Schaumberger , Preparing adult patients for cardiac catheterization: informational treatment and coping style interactions. Heart Lung 23 (1994), pp. 130-139.

16. E.C. Devine, Effects of psychoeducational care for adult surgical patients: a metaanalysis of 191 studies. Patient Educ. Couns. 19 (1992), pp. 129-142.

17. S. Ford, L. Fallowfield and S. Lewis, Doctor-patient interactions in oncology. Soc. Sci. Med. 42 (1996), pp. 1511-1519.

18. E. Mudde and M. Fahrenfort , Wat vinden patiënten van de voorlichting in het ziekenhuis? (What do patients think of education in hospital)?. TVZ 43 (1989), pp. 710-716.

19. D. Lamarche, R. Taddeo and C. Pepler , The preparation of patients for cardiac surgery. Clin. Nurs. Res. 7 (1998), pp. 390-405.

20. M.A. Stewart , Effective physician-patient communication and health outcomes: a review. Can. Med. Ass. J. 152 (1996), pp. 1423-1433.

21. Wagner C. Implementation and effectiveness of quality systems in Dutch health care organizations. Utrecht: Nivel, 1999.

22. Van den Brink-Muinen A, Verhaak PFM, Bensing JM, Bahrs O, Deveugele M, Gask L, Mead N, Leiva-Fernandes F, Perez A, Messerli V, Oppizzi L, Peltenburg M. The Eurocommunication study: an international comparative study in six European countries on doctor-patient communication in general practice. Utrecht: Nivel, 1999.

23. Kruijver IPM. Communication between nurses and admitted cancer patients: the evaluation of a communication training program. Utrecht: Nivel, 2001.

Corresponding author. Tel.: +31-30-272-9661; fax: +31-30-272-9729. 
TABLES

Table 1. Categories of the observation scheme

\begin{tabular}{|c|c|c|}
\hline Proxider categneries & Fatient calegories & Exomples \\
\hline \multicolumn{3}{|l|}{ Nedienl iopes } \\
\hline 1. Medical history taking & $\begin{array}{l}\text { Information abent medical } \\
\text { history }\end{array}$ & Preniows surgerhs, alliggy, parie \\
\hline $\begin{array}{l}\text { 2, Questions about med- } \\
\text { iention }\end{array}$ & $\begin{array}{l}\text { Infoumation about medien- } \\
\text { ion }\end{array}$ & Use of medicuhon, nathe dese \\
\hline $\begin{array}{l}\text { 3. Medical informaticm } \\
\text { about sungery }\end{array}$ & $\begin{array}{l}\text { Afedical qrestiens abeut } \\
\text { surgery }\end{array}$ & Anaesthesida, surgery fechnie \\
\hline $\begin{array}{l}\text { 4. Oher medical infor } \\
\text { mation } \\
\text { Nursing topics }\end{array}$ & Other medieal questions & Ehees on odher Hhesses \\
\hline $\begin{array}{l}\text { 5. General infomation } \\
\text { about ward }\end{array}$ & Questions about ward & Wisting hoks, roonr, mFethines \\
\hline $\begin{array}{l}\text { 6. Preparation for } \\
\text { surgery }\end{array}$ & $\begin{array}{l}\text { Questions about prepara- } \\
\text { ion }\end{array}$ & Sharving, forting, foking offlewels \\
\hline $\begin{array}{l}\text { 7. Hespifal stay aftex } \\
\text { surgery } \\
\text { Healh education topics }\end{array}$ & $\begin{array}{l}\text { Questions about stay affer } \\
\text { surgery }\end{array}$ & Rehoblingtion. knght of stay, prin \\
\hline s, Funily education & $\begin{array}{l}\text { Practical information fiom } \\
\text { relafives }\end{array}$ & Phone calls dheing difter stargery \\
\hline $\begin{array}{l}\text { 9. Pratical infonmatiom } \\
\text { about suigery } \\
\text { Oher fopics }\end{array}$ & $\begin{array}{l}\text { Practical questions about } \\
\text { surgery }\end{array}$ & Swgery sehedute. FCE rwhes \\
\hline 10. Social ialk & Social ialk & Greftings. joking. chatfing \\
\hline 11. Lifestyle questions & Lifestyle information & LWheng shimarion, stwoking, alsohal \\
\hline 12, Lifastyle advice & Questions about lifestyle & Drhing, biking waking, hotsehald \\
\hline $\begin{array}{l}\text { 13. Psycho-secial } \\
\text { questions }\end{array}$ & Psyehe-social information & Exrofionel well-beling, concerns \\
\hline $\begin{array}{l}\text { 14. Psyeho-social } \\
\text { infomation }\end{array}$ & Psyche-social questions & Ensorionat ensequeness \\
\hline 15. Check & & Assessing knewhedge betiefs \\
\hline $\begin{array}{l}\text { 16. Information about vo- } \\
\text { day's pregram }\end{array}$ & & Which prowiders welt eonse round \\
\hline 17. Other & Other & Inarnd ible aftermiess \\
\hline
\end{tabular}

Coherent clusters of the provider and the patient communication are presented in the same row. 
Weert, J. van, Dulmen, S. van, Bar, P., Venus, E. Interdisciplinary preoperative patient education in cardiac surgery. Patient Education and Counseling: 2003, 49(2), 105-114

Table 2. Characteristics of encounters by the different health care providers

\begin{tabular}{|c|c|c|c|}
\hline & Phzsician nean (S.D.) & Nurse mean (S.D.) & Healih eduedtar mean (S.D.) \\
\hline Yisit lexghth (min) & $26.0(10.2)$ & $32.8(10.7)$ & $12.8(5 . \bar{D})$ \\
\hline $\begin{array}{l}\text { Physlexl expulnaten } \\
\text { lengh (min) }\end{array}$ & $7.7(23)$ & $=-$ & m \\
\hline Previdar contribution (\%) & $379(13.8)$ & $523(9.1)$ & $78.5(16.1)$ \\
\hline Patient combibolien $(\%)$ & $30.2(10.3)$ & $30.7(9.2)$ & 10.8 $(6.6)$ \\
\hline Silanee $\cos \gamma^{\circ}$ & $31.1(11.9)$ & $16.7(6.7)$ & $8.3(3.5)$ \\
\hline Iniemption (s) & $09(2.5)$ & $02(0.6)$ & $1.5(5.9)$ \\
\hline
\end{tabular}

Table 3. Percentages and standard deviations of time spent on specific topics during different health care encounters

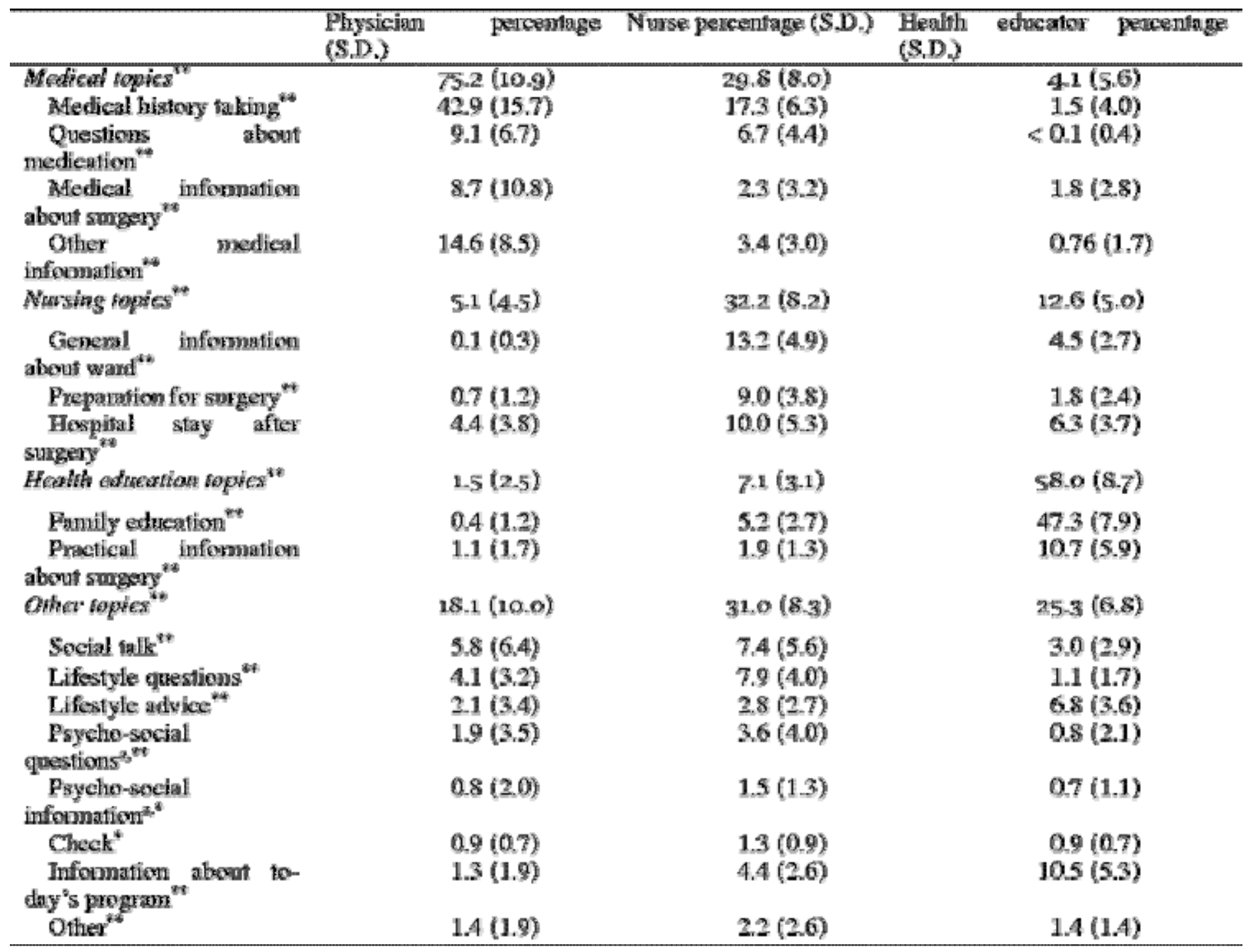

Relative to the total time per health care encounter 
Weert, J. van, Dulmen, S. van, Bar, P., Venus, E. Interdisciplinary preoperative patient education in cardiac surgery. Patient Education and Counseling: 2003, 49(2), 105-114

Table 4. Number and percentages of patients receiving psycho-educational information and questions by the different health care providers

\begin{tabular}{|c|c|c|c|c|c|c|c|c|c|c|}
\hline & \multicolumn{2}{|c|}{ Kothphysicien and nurse } & \multicolumn{2}{|c|}{ Physician ody } & \multicolumn{2}{|c|}{ Nuse enly } & \multicolumn{2}{|c|}{ Healo edacator only } & \multicolumn{2}{|c|}{ Nat asked domentivned } \\
\hline & A & Rerecmage & $A$ & Peremtage & $B$ & क & 5 & Percentage & 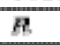 & Pereeniage \\
\hline 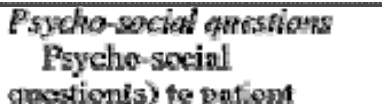 & 2 & 39 & 2 & 3,9 & 21 & 412 & (1) & 0.0 & 26 & 51.0 \\
\hline $\begin{array}{l}\text { Poycho-social } \\
\text { question(s) to relstives }\end{array}$ & 0 & 0.0 & 1 & 2.0 & 7 & 13.7 & 6 & 0.0 & 43 & 84,3 \\
\hline $\begin{array}{l}\text { Ptiens" well-being } \\
\text { Psycho-socid infornedion }\end{array}$ & 2 & 39 & 2 & 39 & 2 & 3.9 & 1 & 20 & 44 & 86.3 \\
\hline $\begin{array}{l}\text { Psyche-sckial } \\
\text { consequences of cardiae } \\
\text { surgery for patient during } \\
\text { admission }\end{array}$ & $\theta$ & 0.0 & $\underline{2}$ & 3.9 & 9 & 17.6 & 1 & 2.0 & 39 & 76.5 \\
\hline 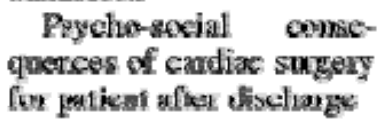 & 0 & 0.0 & 1 & 2.0 & 1 & 2.0 & (i) & 0.0 & 49 & $96: 1$ \\
\hline $\begin{array}{l}\text { Pryeho-soeial } \\
\text { consequences of cordiac } \\
\text { surgery for selatives } \\
\text { Cheds }\end{array}$ & 0 & 0.0 & 0 & 0,0 & 3 & 5.9 & 1 & 2,0 & 47 & 922 \\
\hline $\begin{array}{l}\text { Assessment of knowel- } \\
\text { adge abeut awgery }\end{array}$ & 3 & 5.9 & 3 & 5.9 & 17 & 333 & (4) & 0.0 & 28 & 54,9 \\
\hline $\begin{array}{l}\text { Assessment of expecta } \\
\text { tions }\end{array}$ & $\theta$ & 0,0 & 0 & 0.0 & 12 & 23.5 & a & 0.0 & 39 & 765 \\
\hline $\begin{array}{l}\text { Assessment of under- } \\
\text { standing }\end{array}$ & 1 & 2.0 & 0 & 0.0 & 11 & 21.6 & 1 & 2.0 & 38 & 74.5 \\
\hline
\end{tabular}

$$
\mathrm{N}=51 \text {. }
$$

Table 5. Number and percentages of patients receiving specific questions by different health care providers

\begin{tabular}{|c|c|c|c|c|c|c|c|c|}
\hline & \multicolumn{2}{|c|}{ Botly physician and ourse } & \multicolumn{2}{|c|}{ Pbysician only } & \multicolumn{2}{|c|}{ Nunse only } & \multicolumn{2}{|c|}{ Not asked } \\
\hline & $n$ & Pereenfage & $n$ & Pereeniage & na & Pereentage & $R$ & Pereentage \\
\hline Uas of medication & 35 & 686 & 4 & 78 & 10 & 19.6 & 2 & 3.9 \\
\hline Symptoms & 34 & 667 & 1 & 20 & 14 & 27.5 & 2 & 3.9 \\
\hline Other health cane problems. & 41 & 904 & 3 & 15.7 & 2 & 3.9 & 0 & 00 \\
\hline Previous sprgeries & 31 & 60.8 & 16 & 31.4 & 1 & 2,0 & 3 & 5.9 \\
\hline $\begin{array}{l}\text { Which ofler hespi- } \\
\text { talsf́physicians }\end{array}$ & 19 & 37.3 & 12 & 73.5 & 8 & 15.7 & 12 & 235 \\
\hline Sef of dephares & 26 & 510 & 3 & 59 & 19 & 37.3 & 3 & 5.9 \\
\hline Sense of heang & 7 & 13.7 & 1 & 20 & 30 & 39.2 & 23 & 45.1 \\
\hline Alkngy & 43 & 843 & 7 & 13.7 & 1 & 2.0 & 0 & 0.0 \\
\hline Lengh/weight & 10 & 196 & 16 & 31.4 & 7 & 13.7 & 18 & 353 \\
\hline $\begin{array}{l}\text { Paticuts ophoion about } \\
\text { transfer to other hospital } \\
\text { after sungery }\end{array}$ & 31 & 67.4 & 7 & 15.2 & 6 & 13.0 & 2 & 4.3 \\
\hline Smoking & 41 & 804 & 9 & 17.6 & 0 & 0.0 & 1 & 2.0 \\
\hline Akeohel consumption & 13 & 25.5 & 4 & 7.8 & 30 & 39.2 & 14 & 27.5 \\
\hline $\begin{array}{l}\text { Home sltualion after } \\
\text { dischages }\end{array}$ & 22 & 43.1 & 6 & 11.8 & 14 & 27.5 & 9 & 17.6 \\
\hline
\end{tabular}

$\mathrm{N}=51$ 